\title{
Stall Flutter Control of a Smart Blade Section Undergoing Asymmetric Limit Oscillations
}

\author{
Nailu Li, ${ }^{1}$ Mark J. Balas, ${ }^{2}$ Pourya Nikoueeyan, ${ }^{3}$ Hua Yang, ${ }^{1}$ and Jonathan W. Naughton ${ }^{3}$ \\ ${ }^{1}$ School of Hydraulic, Energy and Power Engineering, Yangzhou University, Yangzhou, Jiangsu 225127, China \\ ${ }^{2}$ Aerospace Engineering Department, Embry-Riddle Aeronautical University, Daytona Beach, FL 32114-3900, USA \\ ${ }^{3}$ Wind Energy Center, University of Wyoming, Laramie, WY 82072, USA \\ Correspondence should be addressed to Nailu Li; nellylee85101@163.com
}

Received 14 November 2015; Revised 10 February 2016; Accepted 23 February 2016

Academic Editor: Gianluca Gatti

Copyright (C) 2016 Nailu Li et al. This is an open access article distributed under the Creative Commons Attribution License, which permits unrestricted use, distribution, and reproduction in any medium, provided the original work is properly cited.

\begin{abstract}
Stall flutter is an aeroelastic phenomenon resulting in unwanted oscillatory loads on the blade, such as wind turbine blade, helicopter rotor blade, and other flexible wing blades. Although the stall flutter and related aeroelastic control have been studied theoretically and experimentally, microtab control of asymmetric limit cycle oscillations (LCOs) in stall flutter cases has not been generally investigated. This paper presents an aeroservoelastic model to study the microtab control of the blade section undergoing moderate stall flutter and deep stall flutter separately. The effects of different dynamic stall conditions and the consequent asymmetric LCOs for both stall cases are simulated and analyzed. Then, for the design of the stall flutter controller, the potential sensor signal for the stall flutter, the microtab control capability of the stall flutter, and the control algorithm for the stall flutter are studied. The improvement and the superiority of the proposed adaptive stall flutter controller are shown by comparison with a simple stall flutter controller.
\end{abstract}

\section{Introduction}

Stall flutter is a nonlinear aeroelastic phenomenon with selfexcited oscillation of limited amplitude. Those oscillations are called limit cycle oscillations (LCOs). And stall flutter is a LCO occurring as a result of the dynamic stall, which is an aerodynamic nonlinearity [1]. Two dynamic stall regimes are defined [2]: moderate stall and deep stall. Moderate stall is a phenomenon similar to static stall. Deep stall is characterized by the maximum lift and moment values far in excess of their static counterparts. The oscillations of stall flutter associated with moderate stall or deep stall can result in large oscillatory fatigue loads on the wind turbine blade or helicopter rotor blade and thus reduce blade life span as well as harming the safety and the efficiency of the blade operation. Therefore, there had been an interest in the stall flutter suppression for years.

For the past decades, flutter control has been studied by a number of researchers. Yan and Xin [3] studied the oscillatory blowing control of the airfoil flutter by numerical simulation.
Nonlinear control methods were reviewed by Kurdila and Akella [4] for high-energy limit cycle oscillations. They concluded that full and partial feedback control or nonlinear model reference adaptive control (MRAC) methodologies were effective to control LCOs. Strganac et al. [5] suggested the adaptive control as the appropriate control strategy for limit cycle oscillations in aeroelastic systems. Those studies mainly emphasized the design of the control algorithms.

Recently, there has been an increasing interest in flutter control via the smart blade, which is the blade equipped with the appropriate and deployed actuator [6]. Various kinds of such actuators have been investigated for flutter suppression. Tang and Dowell [7] completed the LCO suppression of a high-aspect ratio wing by a controllable slender body tip mass distribution. Li and Fleeter [8] adopted piezoelectric actuators for active suppression of nonlinear stall flutter, including limit cycle and chaotic and quasi-periodic separated flow induced airfoil vibration. Sun et al. [9] studied stall flutter and flutter suppression control systems with a novel state-space model description. Liu [10] investigated blade pitch actuation 
in the aeroservoelastic control of stall-induced flutter of wind turbine blade section. In addition, the trailing edge flap has been widely used as the control surface to reject the unwanted oscillatory loads and control the aeroelastic instability of the blade [11-13].

However, the flutter control using the microtab is rarely studied. The microtab, earlier proposed by Yen et al. [14], is simply short flat plates (approximately $1-5 \%$ of the airfoil chord in height) attached to the trailing edge perpendicular to the chord line on the pressure or suction side of the airfoil. In contrast to many other actuators for addressing blade loading issues that seem to be complex and energy-consuming, the potential for the microtab to regulate blade loads with high efficiency has been numerically and experimentally studied by researchers [15-20]. The author has also made several studies on microtab control. First, the effect of microtab was studied to control small sinusoidal aerodynamic loads on the blade section [21]. Then, the microtab was used to control aerodynamic load of the blade section at low wind speeds associated with operating regions of a typical wind turbine $[22,23]$. The microtab controller was also designed to have full controllability on pitch motion [24]. Moreover, the microtab was recently investigated for the control of classic flutter at relatively small angle of attack [25].

However, the microtab control of the blade section undergoing dynamic stall has not been studied extensively. In most of the previous works with microtab control application, the static aerodynamic force coefficients have been considered as a baseline for the airfoil loading behavior or a small and smooth change in the unsteady aerodynamic loading to control the aeroelastic response of the blade section only in the attached flow. Nevertheless, it has been proved that, with the occurrence of the dynamic stall, the airfoil section suffers a dramatic change in aerodynamic loads in short time intervals, which will worsen the control effect and even cause the instability of the control system. Thus, it is essential to develop new microtab controller to address stall flutter in different dynamic stall regimes.

The purpose of the present work is to investigate a new microtab controller to suppress the asymmetric LCOs in moderate stall flutter and deep stall flutter conditions. The dynamic moderate/deep stall of the blade section will be simulated via the Beddoes-Leishman dynamic stall model and validated by the static test curves. The consequent limit cycle oscillations of the moderate/deep stall flutter will be studied by analyzing the time-domain responses and phase plane results. The design of the stall flutter controller with microtab actuator includes the sensor signal study, the microtab control capability analysis, and the stall flutter control algorithm design. The control results of the proposed controller are compared with the simple stall flutter controller to show its improvement and effectiveness in both dynamic stall conditions.

\section{Aeroelastic Model of Stall Flutter System}

In this study, an aeroelastic model of the blade section shown in Figure 1 is used for aeroelastic analysis and control design. This is a typical two-dimensional wing section with

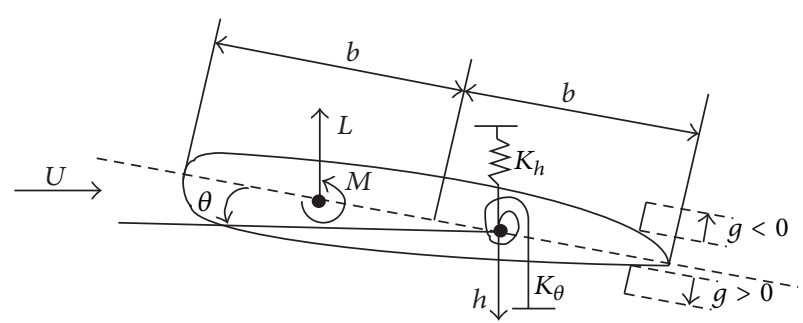

FIgURE 1: Typical two-dimensional blade section.

two degrees of freedom, that is, the plunge motion and the pitch motion. The plunge motion is defined by the plunge displacement $h$ with the direction of positive downwards, and the pitch motion is defined by the pitch angle $\theta$ with the direction of positive nose down. The aerodynamic control device, microtabs, is installed close to the trailing edge of the blade. The microtab deployment height $g$, is regarded as a control input to the system and acts in a similar way to the gurney flap. $b$ is the mid-chord length. $K_{h}$ and $K_{\theta}$ are plunge stiffness and pitch stiffness, restricted to the elastic axis and $C_{h}$ and $C_{\theta}$ are the plunge and pitch damping coefficients. The section is exposed to the aerodynamic forces $L$ and aerodynamic moment $M$ at the aerodynamic centre.

2.1. Dynamic Stall Model. To include the loading from the unsteady dynamic stall phenomena, the Beddoes-Leishman (B-L) model is adopted to account for the effect of the separated flow at the stall region. Since the basic assumption in B-L model of static lift for trailing edge separation is the lift on a flat plate in a potential Kirchhoff flow, the separation point $f^{\text {st }}$ can be defined as follows [26]:

$$
f^{\mathrm{st}}=\left(2 \sqrt{\frac{C_{L}^{\mathrm{st}}(\alpha)}{C_{L, \alpha}\left(\alpha-\alpha_{0}\right)}-1}\right)^{2} \text {, }
$$

where $C_{L}^{\text {st }}$ is the static lift coefficient for the airfoil and $f^{\text {st }}$ indicates a fully separated flow when it equals zero.

Based on the separation point, the fully separated flow is described as

$$
C_{L}^{\mathrm{fs}}=\frac{C_{L}^{\mathrm{st}}-C_{L, \alpha}\left(\alpha-\alpha_{0}\right) f^{\mathrm{st}}}{1-f^{\mathrm{st}}} .
$$

Note that there will be a problem when $f^{\text {st }}=1$. The value of $C_{L}^{\mathrm{fs}}$ can be approximated as $C_{L}^{\text {st }}(\alpha) / 2$ when $f^{\text {st }}$ gets close to one.

The dynamic behavior of the trailing edge separation can be described by the separation related to the pressure distribution over the airfoil section and the separation due to the dynamics of the boundary layer. For the pressure distribution separation, it is assumed that there is a time lag between the unsteady lift coefficient $C_{L}^{P^{\prime}}$ and the actual lift coefficient $C_{L}^{P}$. The unsteady lift coefficient is modeled as

$$
\dot{C}_{L}^{P^{\prime}}+T_{p}^{-1} C_{L}^{P^{\prime}}=T_{p}^{-1} C_{L}^{p}(t),
$$


where $T_{p}$ is the time constant for the pressure lag and $C_{L}^{P}=$ $2 \pi\left(\alpha_{E}-\alpha_{0}\right)+\pi b \theta / \dot{U}, \alpha_{0}$ is the angle of attack at zero lift.

The overall dynamics of the flow separation can be revealed by the unsteady separation point, which is caused by the boundary layer dynamics, and involves the effect of the pressure distribution. The equation for the unsteady separation point $f^{\text {dy }}$, which makes the separation point lag behind the quasi-steady value $f^{\mathrm{qs}}$, is given as

$$
\dot{f}^{\mathrm{dy}}+T_{f}^{-1} f^{\mathrm{dy}}=T_{f}^{-1} f^{\mathrm{qs}}(t),
$$

where $T_{f}$ is the time delay in the boundary layer; the equivalent quasi-steady separation point $f^{\mathrm{qs}}=f^{\mathrm{st}}\left(\alpha_{f}\right), \alpha_{f}=$ $C_{L}^{P^{\prime}} / C_{L, \alpha}+\alpha_{0}$, is an equivalent angle of attack that gives the same quasi-steady value of unsteady lift coefficient $C_{L}^{P^{\prime}}$.

The unsteady aerodynamic forces of the blade section in stall should involve the unsteady forces induced by both attached flow and the separation flow. The unsteady lift curve can be represented by a liner interpolation between the lift for the fully attached flow and the lift for the fully separated flow as

$$
L_{s}=\rho U^{2} b C_{L 0}+L_{1} f^{\mathrm{dy}}+\rho U^{2} b C_{L}^{\mathrm{fs}}\left(\alpha_{E}\right)\left(1-f^{\mathrm{dy}}\right),
$$

where $L_{s}$ is the unsteady lift including the effect of trailing edge separation, $C_{L 0}$ is the static lift coefficients at zero angle of attack, $L_{1}$ is the lift for the fully attached flow, and $\alpha_{E}$ is the effective angle of attack and can be given as

$$
\begin{aligned}
\alpha_{E}(t)= & \left(\frac{b \dot{h}(t)}{U}+\theta(t)+\frac{b \dot{\theta}(t)}{U}\right)\left(1-A_{1}-A_{2}\right)+x_{1} \\
& +x_{2}, \\
x_{1}= & b_{1} A_{1} \frac{1}{b U} \int_{0}^{t} \omega_{3 / 4}\left(t^{\prime}\right) U\left(t^{\prime}\right) e^{-b_{1} / b \int_{t^{\prime}}^{t} U(\tau) d \tau} d t^{\prime}, \\
x_{2}= & b_{2} A_{2} \frac{1}{b U} \int_{0}^{t} \omega_{3 / 4}\left(t^{\prime}\right) U\left(t^{\prime}\right) e^{-b_{2} / b \int_{t^{\prime}}^{t} U(\tau) d \tau} d t^{\prime},
\end{aligned}
$$

where $x_{1}$ and $x_{2}$, yielding the effective downwash, are two state variables of the attached flow; $\omega_{3 / 4}$ is the downwash at the three-quarter point. $A_{1}, A_{2}, b_{1}$, and $b_{2}$ are constant, indicating two time lags in Wagner function of $\phi(s)=1-$ $A_{1} e^{-b_{1} s}-A_{2} e^{-b_{2} s}$

The unsteady moment is affected by the trailing edge separation through movement of the pressure center due to the separation. Define the equivalent pressure center as

$$
a^{\text {st }}=\frac{\left(C_{M}^{\mathrm{st}}-C_{M_{0}}\right)}{C_{L}^{\mathrm{st}}},
$$

where $C_{M}^{\text {st }}$ and $C_{L}^{\text {st }}$ are the static lift and moment coefficient and $C_{M_{0}}$ is the moment coefficient at zero lift. Thus, the unsteady moment is given as

$$
\begin{aligned}
M_{s}= & 2 \rho U^{2} b^{2} C_{M 0}+M_{1} \\
& +2 \rho U^{2} b^{2}\left(L_{s}\left(a^{\text {st }}\left(f^{\text {dy }}\right)-a^{\text {st }}\left(f^{\text {st }}\left(\alpha_{E}\right)\right)\right)\right),
\end{aligned}
$$

where the first term is the static moment at zero angle of attack, the second term $M_{1}$ is the moment for the fully attached flow, and the last term is the unsteady moment due to the dynamic trailing edge separation.

Assume that the dynamic stall model is linearized with small amplitude vibrations about the equilibrium, given by the steady angle of attack $\alpha^{0}$. Then the linearized unsteady lift and moment using Taylor expansion about the steady angle of attack are approximated as

$$
\begin{aligned}
L_{s}= & \rho U^{2} b C_{L}^{0}+L_{1} f_{0} \\
& +\rho U^{2} b \alpha_{E}\left(\left.\frac{d C_{L}^{\mathrm{fs}}}{d \alpha}\right|_{\alpha=\alpha^{0}}\left(1-f_{0}\right)\right) \\
& +\rho U^{2} b\left(C_{L, \alpha}\left(\alpha^{0}-\alpha_{0}\right)-C_{L}^{\mathrm{fs}}\left(\alpha^{0}\right)\right) f^{\mathrm{dy}}, \\
M_{s}= & 2 \rho U^{2} b^{2} C_{M}^{0}+M_{1} \\
& -2 \rho U^{2} b^{2} \alpha_{E}\left(\left.\left.C_{L}^{0} \frac{d f^{\mathrm{st}}}{d \alpha}\right|_{\alpha=\alpha^{0}} \frac{d a^{\mathrm{st}}}{d f}\right|_{\alpha=\alpha^{0}}\right) \\
& +\left.2 \rho U^{2} b^{2} C_{L}^{0} \frac{d a^{\mathrm{st}}}{d f}\right|_{\alpha=\alpha^{0}} f^{\mathrm{dy}},
\end{aligned}
$$

where $C_{L}^{0}$ and $C_{M}^{0}$ are the static lift and moment coefficients at the steady angle of attack. $f_{0}$ is the static separation point at the steady angle of attack. The details of the formulation of the attached lift $L_{1}$ and moment $M_{1}$ can be found in the literature [25].

2.2. Governing Equations of the System. With the dynamic stall modeled in the previous section, the equations of the pitch and plunge motions of the smart blade section undergoing the stall dynamics are as follows:

$$
\begin{gathered}
{\left[\begin{array}{cc}
m & m b x_{\theta} \\
m b x_{\theta} & I_{\theta}
\end{array}\right]\left[\begin{array}{l}
\ddot{h} \\
\ddot{\theta}
\end{array}\right]+\left[\begin{array}{cc}
C_{h} & 0 \\
0 & C_{\theta}
\end{array}\right]\left[\begin{array}{c}
\dot{h} \\
\dot{\theta}
\end{array}\right]} \\
+\left[\begin{array}{cc}
K_{h} & 0 \\
0 & K_{\theta}
\end{array}\right]\left[\begin{array}{l}
h \\
\theta
\end{array}\right]=\left[\begin{array}{c}
-L_{s} \\
M_{s}
\end{array}\right]+\left[\begin{array}{c}
-L_{g} \\
M_{g}
\end{array}\right],
\end{gathered}
$$

where $m$ is the mass of the airfoil section, $x_{\theta}$ is the dimensionless distance between the elastic axis and the mass center, and $I_{\theta}$ is the inertia moment about the elastic axis.

Define $z=\left[\begin{array}{ll}h & \theta\end{array}\right]^{T}, F=\left[\begin{array}{ll}-L_{s} & M_{s}\end{array}\right]^{T}$, and $F_{g}=$ $\left[\begin{array}{ll}-L_{g} & M_{g}\end{array}\right]^{T} ;(11)$ of the structural model can be rewritten in the form as

$$
M_{0} \ddot{z}+C_{0} \dot{z}+K_{0} z=F+F_{g}
$$

where $F$ is the unsteady aerodynamic forces, $F_{g}$ is the aerodynamic forces due to control surface, $L_{g}=\rho U^{2} b C_{L, g} g$ and $M_{g}=2 \rho U^{2} b^{2} C_{M, g} g$ represent the change in the airfoil lift and pitching moment due to the microtab deployment, and $C_{L, g}$ and $C_{M, g}$ are the corresponding aerodynamic coefficients. These coefficients were calculated by numerical simulation using the commercial CFD code, FLUENT. 
Defining $X_{a}$ as the vector of $x_{1}$ and $x_{2}$ and $X_{s}$ as the vector of $C_{L}^{P^{\prime}}$ and $f^{\text {dy }},(10)$ can be rewritten in the matrix form as

$$
F=\left[\begin{array}{c}
-L_{s} \\
M_{s}
\end{array}\right]=D_{1} z+D_{2} \dot{z}+C_{1} X_{a}+C_{2} X_{s}+C_{0}
$$

where

$$
\begin{aligned}
& D_{1}=\left[\begin{array}{cc}
0 & -\rho \mathrm{U}^{2} b\left(\bar{a} C_{L, \alpha} f_{0}+\bar{a} C_{L, \alpha^{0}}^{\mathrm{fs}}\left(1-f_{0}\right)\right) \\
0 & 2 \rho U^{2} b^{2}\left(\bar{a} C_{M, \alpha^{0}}^{\mathrm{st}}-\bar{a} C_{L}^{0} f_{\alpha^{0}}^{\mathrm{st}} a_{\alpha^{0}}^{\mathrm{st}}\right)
\end{array}\right], \\
& D_{2}=\left[\begin{array}{cc}
-\rho U \bar{a} b^{2}\left(C_{L, \alpha} f_{0}+C_{L, \alpha^{0}}^{\mathrm{fs}}\left(1-f_{0}\right)\right) & -\rho U \bar{a} b^{2}\left(C_{L, \alpha} f_{0}+C_{L, \alpha^{0}}^{\mathrm{fs}}\left(1-f_{0}\right)+\frac{\pi}{\bar{a}}\right) \\
2 \rho U \bar{a} b^{3}\left(C_{M, \alpha^{0}}^{\mathrm{st}}-C_{L}^{0} f_{\alpha^{0}}^{\text {st }} a_{\alpha^{0}}^{\mathrm{st}}\right) & 2 \rho U \bar{a} b^{3}\left(C_{M, \alpha^{0}}^{\mathrm{st}}-C_{L}^{0} f_{\alpha^{0}}^{\mathrm{st}} a_{\alpha^{0}}^{\mathrm{st}}-\frac{\pi}{2 \bar{a}}\right)
\end{array}\right] \text {, } \\
& C_{1}=\left[\begin{array}{cc}
-\rho U^{2} b\left(C_{L, \alpha} f_{0}+C_{L, \alpha^{0}}^{\mathrm{fs}}\left(1-f_{0}\right)\right) & -\rho U^{2} b\left(C_{L, \alpha} f_{0}+C_{L, \alpha^{0}}^{\mathrm{fs}}\left(1-f_{0}\right)\right) \\
2 \rho U^{2} b^{2}\left(C_{M, \alpha^{0}}^{\mathrm{st}}-C_{L}^{0} f_{\alpha^{0}}^{\text {st }} a_{\alpha^{0}}^{\text {st }}\right) & 2 \rho U^{2} b^{2}\left(C_{M, \alpha^{0}}^{\text {st }}-C_{L}^{0} f_{\alpha^{0}}^{\text {st }} a_{\alpha^{0}}^{\text {st }}\right)
\end{array}\right] \text {, } \\
& C_{2}=\left[\begin{array}{cc}
0 & -\rho U^{2} b\left(C_{L, \alpha}\left(\alpha^{0}-\alpha_{0}\right)-C_{L}^{\mathrm{fs}}\left(\alpha^{0}\right)\right) \\
0 & 2 \rho U^{2} b^{2} C_{L}^{0} a_{\alpha^{0}}^{\text {st }}
\end{array}\right] \text {, } \\
& C_{0}=\left[\begin{array}{c}
-\rho U^{2} b C_{L}^{0} \\
2 \rho U^{2} b^{2} C_{M}^{0}
\end{array}\right], \\
& \bar{a}=1-A_{1}-A_{2} \text {, } \\
& C_{L, \alpha^{0}}^{\mathrm{fs}}=\left.\frac{d C_{L}^{\mathrm{fs}}}{d \alpha}\right|_{\alpha=\alpha^{0}}, \\
& C_{M, \alpha^{0}}^{\mathrm{st}}=\left.\frac{d C_{M}^{\mathrm{st}}}{d \alpha}\right|_{\alpha=\alpha^{0}}, \\
& f_{\alpha^{0}}^{\mathrm{st}}=\left.\frac{d f^{\mathrm{st}}}{d \alpha}\right|_{\alpha=\alpha^{0}}, \\
& a_{\alpha^{0}}^{\text {st }}=\left.\frac{d a^{\text {st }}}{d f}\right|_{\alpha=\alpha^{0}} \text {. }
\end{aligned}
$$

With the definition of $X_{a}$ and $X_{s},(3),(4),(6)$, and (7) of the aerodynamic stall model can be rewritten in the statespace forms as

$$
\begin{aligned}
& \dot{X}_{s}=A_{3} X_{a}+A_{4} X_{s}+B_{3} z+B_{4} \dot{z}, \\
& \dot{X}_{a}=A_{1} X_{a}+A_{2} X_{s}+B_{1} z+B_{2} \dot{z},
\end{aligned}
$$

where

$$
\begin{aligned}
& A_{1}=\left[\begin{array}{cc}
-T_{1}^{-1} & 0 \\
0 & -T_{2}^{-1}
\end{array}\right], \\
& A_{2}=\left[\begin{array}{ll}
0 & 0 \\
0 & 0
\end{array}\right] \\
& A_{3}=\left[\begin{array}{cc}
T_{p}^{-1} C_{L, \alpha} & T_{p}^{-1} C_{L, \alpha} \\
0 & 0
\end{array}\right],
\end{aligned}
$$

$$
\begin{aligned}
& A_{4}=\left[\begin{array}{cc}
-T_{p}^{-1} & 0 \\
\frac{T_{f}^{-1}}{C_{L, \alpha}} f_{\alpha^{0}}^{\mathrm{st}} & -T_{f}^{-1}
\end{array}\right], \\
& B_{1}=\left[\begin{array}{ll}
0 & T_{1}^{-1} A_{1} \\
0 & T_{2}^{-1} A_{2}
\end{array}\right],
\end{aligned}
$$$$
B_{2}=\left[\begin{array}{ll}
\frac{T_{1}^{-1} A_{1} b}{U} & \frac{T_{1}^{-1} A_{1} b}{U} \\
\frac{T_{2}^{-1} A_{2} b}{U} & \frac{T_{2}^{-1} A_{2} b}{U}
\end{array}\right],
$$$$
B_{3}=\left[\begin{array}{cc}
0 & \bar{a} T_{p}^{-1} C_{L, \alpha} \\
0 & 0
\end{array}\right] \text {, }
$$$$
B_{4}=\left[\begin{array}{cc}
\frac{\bar{a} b T_{p}^{-1} C_{L, \alpha}}{U} & \frac{\bar{a} b T_{p}^{-1} C_{L, \alpha}}{U}+\frac{\pi T_{P}^{-1} b}{U} \\
0 & 0
\end{array}\right] .
$$ 
The aeroservoelastic model is a combination of the structural model in (12) and the aerodynamic model in (15). Defining the state variables of the system as $q=\left[\begin{array}{llll}z & \dot{z} & X_{a} & X_{s}\end{array}\right]^{T}$, the governing equations of the aeroservoelastic model can be written in state-space form as

$$
\left[\begin{array}{c}
\dot{z} \\
\ddot{z} \\
\dot{X}_{a} \\
\dot{X}_{s}
\end{array}\right]=\underbrace{\left[\begin{array}{cccc}
0_{2 \times 2} & I_{2 \times 2} & 0_{2 \times 2} & 0_{2 \times 2} \\
-M_{0}^{-1}\left(K_{0}-D_{1}\right) & -M_{0}^{-1}\left(C_{0}-D_{2}\right) & M_{0}^{-1} C_{1} & M_{0}^{-1} C_{2} \\
B_{1} & B_{2} & A_{1} & A_{2} \\
B_{3} & B_{4} & A_{3} & A_{4}
\end{array}\right]}_{A}\left[\begin{array}{c}
z \\
\dot{z} \\
X_{a} \\
X_{s}
\end{array}\right]+\underbrace{\left[\begin{array}{c}
0_{2 \times 1} \\
G \\
0_{2 \times 1} \\
0_{2 \times 1}
\end{array}\right]}_{B} g,
$$

where

$$
G=\left[\begin{array}{l}
\frac{-\rho U^{2} b I_{\theta} C_{L, g}-2 \rho U^{2} b^{3} m x_{\theta} C_{M, g}}{m I_{\theta}-m^{2} b^{2} x_{\theta}^{2}} \\
\frac{\rho U^{2} b^{2} m x_{\theta} C_{L, g}+2 \rho U^{2} b^{2} m C_{M, g}}{m I_{\theta}-m^{2} b^{2} x_{\theta}^{2}}
\end{array}\right] .
$$

Note that (17) is a linearized equation, with the state matrix $A$, containing the corresponding matrices from the aerodynamic stall model and the structural model.

\section{Stall Conditions and Stall Flutter Analysis}

The purpose of this section is to investigate the effect of different dynamic stall conditions and the consequent aeroelastic behavior of the section undergoing stall flutter. Naughton et al. [27] found that the mean angle of attack is one of the important parameters that affect the behavior of the airfoil in stall significantly. Clearly, the extent of the dynamic stall phenomenon can also affect the aeroelastic behavior of the airfoil. Thus, the study focuses on two different cases of dynamic stall regime. The first case is the moderate stall condition, which holds the mean angle of attack right before the static stall angle $\left(\alpha_{s}=12^{\circ}\right)$. The second case is the deep stall condition, which has the mean angle of attack beyond the static stall angle. In deep dynamic stall condition, large levels of hysteresis exist in the lift and moment coefficient curves, as opposed to the moderate dynamic stall case where small hysteresis in aerodynamic coefficients is seen. The aeroelastic behavior of the airfoil induced by both cases will be discussed. In order to investigate aeroelastic stability, the following model parameters are used [28]: $m=50 \mathrm{~kg}, K_{h}=2884 \mathrm{~N} / \mathrm{m}$, $C_{h}=7.54 \mathrm{~kg} / \mathrm{s}, K_{\theta}=700, C_{\theta}=0.23 \mathrm{kgm}^{2} / \mathrm{s}, I_{\theta}=0.4 \mathrm{~m}^{2} \mathrm{~kg}$, $\rho=1.2 \mathrm{~kg} / \mathrm{m}^{3}$, and $b=0.5 \mathrm{~m}$.

3.1. Moderate Dynamic Stall. Before investigating the aeroelastic response of the airfoil under moderate stall condition, the moderate stall behavior of the blade section needs to be well predicted by the simulation model. The moderate stall aerodynamic curves are simulated based on static experimental data.

Figure 2 shows hysteresis in the dynamic lift and moment curves. The dynamic lift loop has small overshoot based on the static curves, the dynamic moment loop is well surrounding the static curves, and the dynamic curves follow the trend of the static curves as indicated in [26]. For the dynamic lift curve, it is clear that the moderate stall is indicated by a gentle drop between max. point and reattached point and a small time lag between static stall point and max. point. For the dynamic moment curve, there is also a relatively smooth drop between max. point and reattached point. The max. point before the static point is caused by the dynamic moment shape that follows the trend of static curve before the static stall point.

The pitch and plunge responses at moderate stall flutter are shown in Figure 3, where the responses tend to damp at first 30 seconds, and they are stabilized after 40 seconds with asymmetric LCOs (e.g., plunge displacement LCO with magnitude from $0 \mathrm{~m}$ to $-0.5 \mathrm{~m}$ and pitch angle LOC with magnitude from $-5 \mathrm{deg}$. to $-10 \mathrm{deg}$.). This phenomenon is convinced by the experimental results in [1], which indicated the occurrence of only asymmetric LCOs with either positive or negative pitching centering.

3.2. Deep Dynamic Stall. The deep stall aerodynamic curves are also simulated based on static experimental data. Figure 4 shows the deep stall motions of the simulated unsteady lift and moment coefficients at angle of attack $\alpha=13.5^{\circ}+$ $3.5^{\circ} \sin (10 t)$. The deep stall curves are also well predicted by the proposed model to capture the trend of static curves in the neighborhood as expected. In contrast with the moderate stall in Figure 2, the characteristics of deep stall dynamic are revealed by a relatively sharp drop between max. point and reattached point due to the strong separation of the flow and more drastic hysteresis with significant difference between up-stroke and down-stroke phase of dynamic curves. In addition, the maximum lift and moment point are far beyond the static point with a large time lag.

The stall phenomena in Figures 2 and 4 can also be confirmed by the model validation results in [26], where the lift loop near max. point has a very different shape owing to the separation effects, and the lift curve has expected overshoot, while moment curves revolve around the static curves.

Figure 5 shows the pitch and plunge responses at deep stall flutter, where the asymmetric LCOs are also observed 


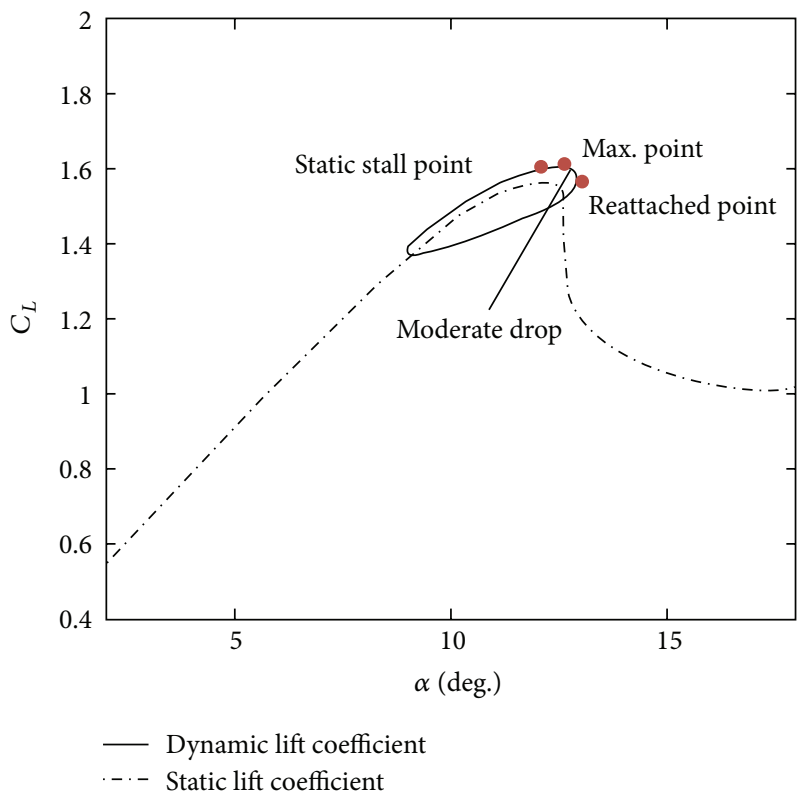

(a)

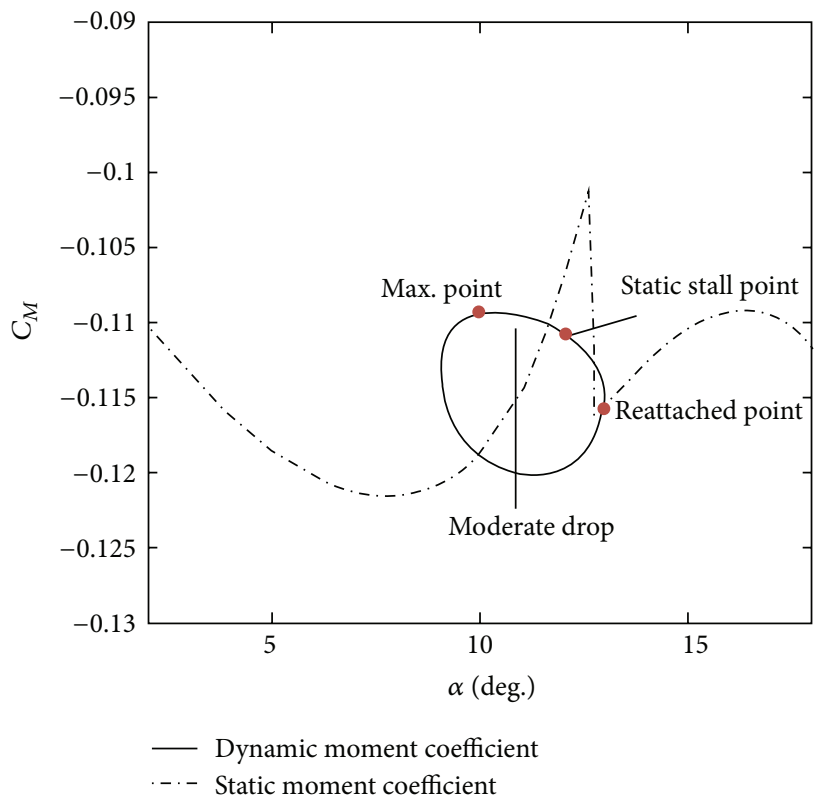

(b)

FIGURE 2: Moderate dynamic stall simulated curve and static experimental data. (a) Lift force coefficient and (b) moment coefficient.
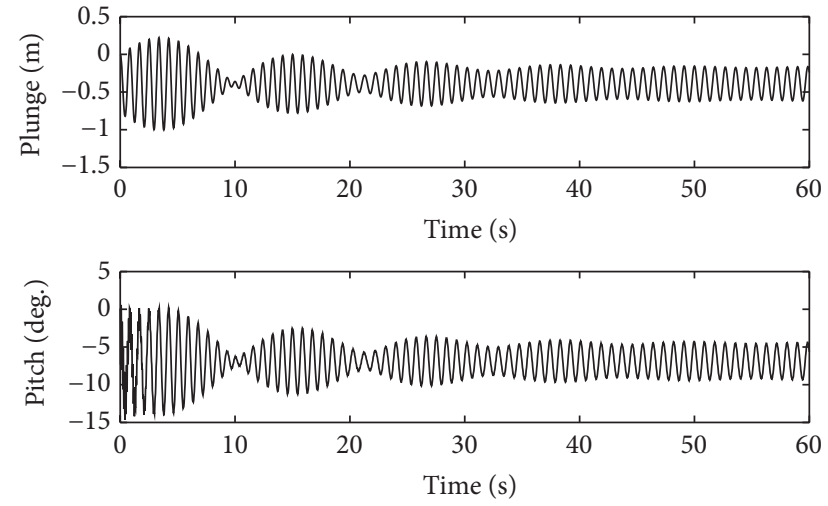

FIGURE 3: Pitch and plunge responses at moderate stall flutter.

and their magnitudes are invariant after 25 seconds, resulting in magnitude of the plunge from $0 \mathrm{~m}$ to $-1 \mathrm{~m}$ and magnitude of the pitch from $-5 \mathrm{deg}$. to $-15 \mathrm{deg}$. Compared with the moderate stall flutter, the deep stall can further decrease the damping ratio of the pitch and plunge modes, leading to relatively larger LCOs in a shorter time.

The $\theta-\dot{\theta}$ phase plane is illustrated in Figure 6 for both moderate stall flutter case and deep stall flutter case. Two asymmetric limit cycle oscillations are observed. It is revealed that the asymmetric LCOs grow in size, and pitching center moves towards the left half of the plane as the section goes through more significant stall hysteresis, which can bring severe oscillations. This phase analysis result is consistent with the results of time-domain responses in Figures 3 and 5 .

\section{Stall Flutter Control}

The purpose of this section is to design the effective controller to suppress the limit cycle oscillations of both moderate stall flutter and deep stall flutter, discussed in the previous section. Since the stall flutter occurs with the unsteady time-varying aerodynamic forces, which is induced by the time-varying change of angle of attack $\alpha^{0}(t)$, the aeroservoelastic system in (17) can be rewritten as

$$
\begin{aligned}
\dot{X} & =A(t) X+B u \\
y & =C X,
\end{aligned}
$$

where $A(t)$ is the state matrix, which holds the coefficients in (17), $u$ is the control input, that is, the microtab deployment of the actuator, and the output sensor signal $y$ can be determined by the output matrix $C$.

4.1. The Test of Former Aeroelastic Controllers. Before the study of the control algorithm for stall flutter control, two former controllers that have been developed by the author in classic flutter control study [25] and pitch control study [24] are first tested on the stall flutter case. Those controllers are also developed with the actuator of the microtab. The aim is to investigate the effectiveness of two former aeroelastic controllers on the new control case, that is, the stall flutter control.

Controller One. It is the classic flutter controller $u=G_{e} y$, $y=\dot{\theta}$. This controller is an output feedback controller, which was shown to be effective in classic flutter suppression of the airfoil section. 


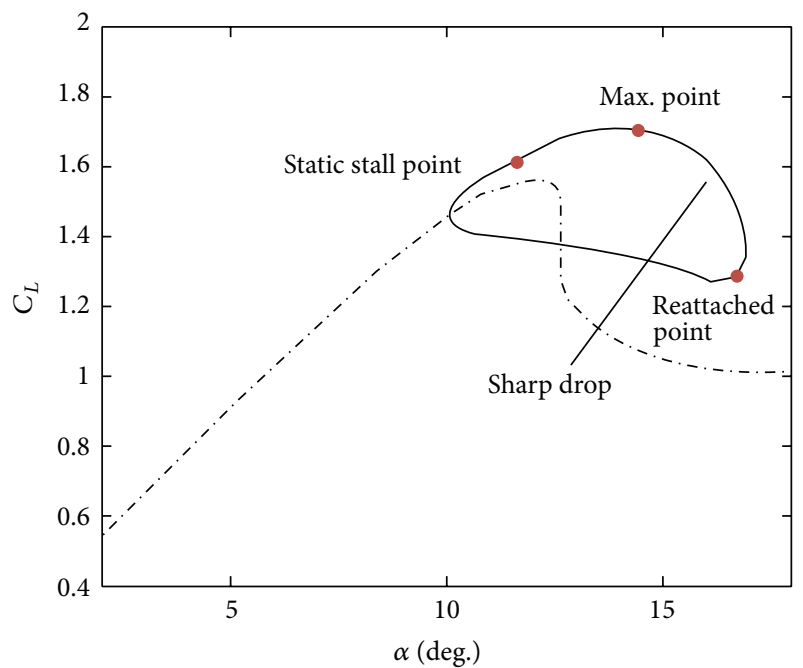

— Dynamic lift coefficient -.- Static lift coefficient

(a)

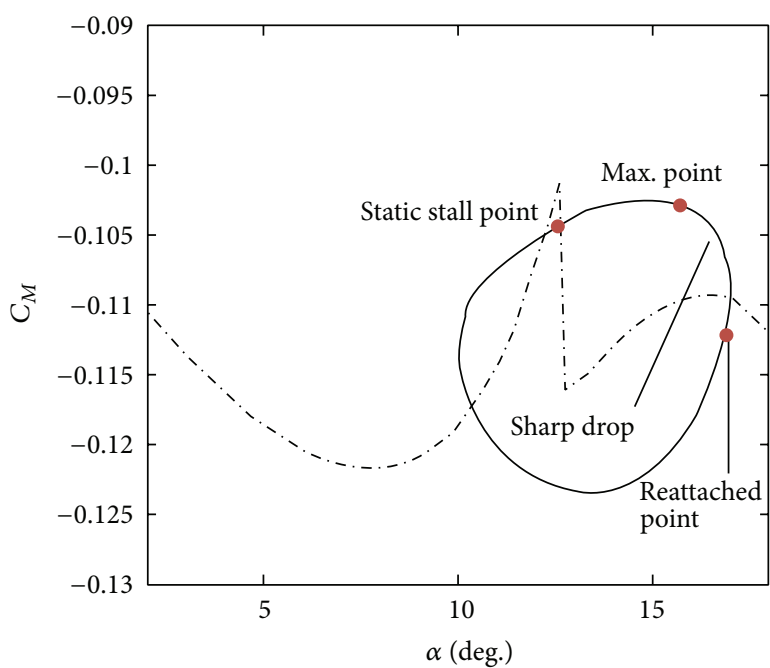

- Dynamic moment coefficient -..- Static moment coefficient

(b)

FIGURE 4: Deep dynamic stall simulated curve and static experimental data. (a) Lift force coefficient and (b) moment coefficient.
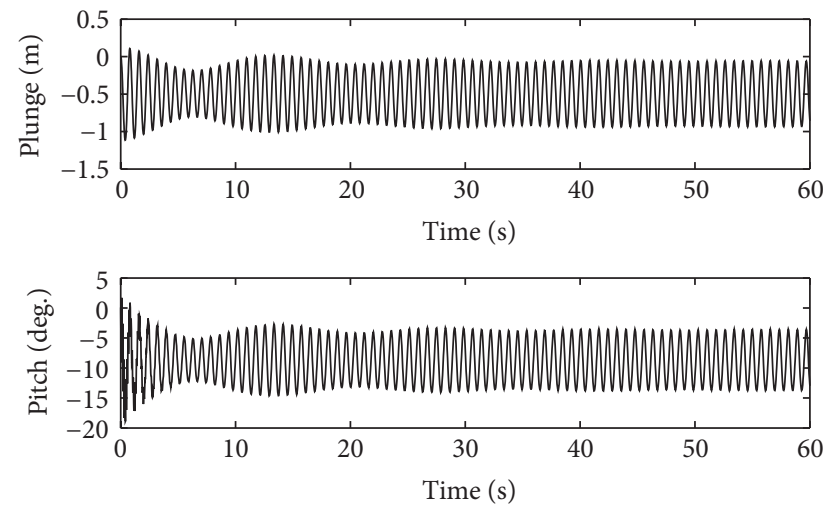

FIGURE 5: Pitch and plunge responses at deep stall flutter.

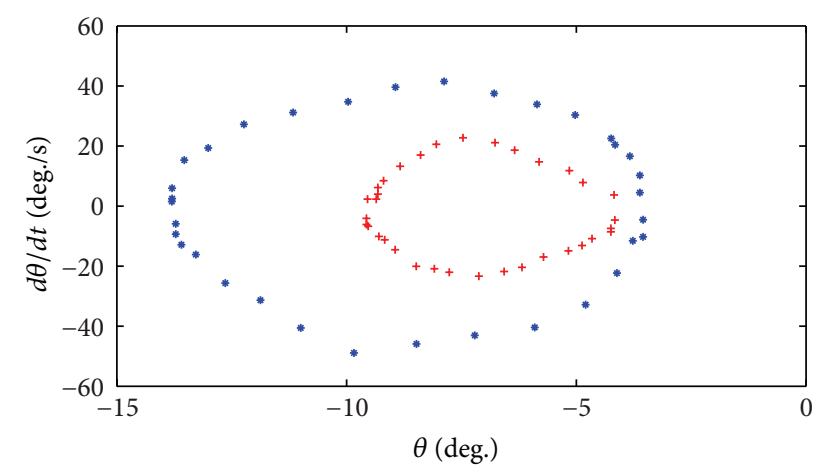

- Deep stall

+ Moderate stall

Figure 6: Phase plane of $\theta$ and $\dot{\theta}$ of the system at moderate/deep stall flutter.
Controller Two. It is the adaptive pitch controller $u=G_{e} y$ $\left(y=\theta+0.1 \dot{\theta}, \dot{G}_{e}=-\gamma_{e} y^{2}\right)$. This adaptive control was proved to have full controllability of pitch mode and partial controllability of plunge mode.

Those two aeroelastic controllers are adopted to control the stall flutter of the blade section separately. The control results are shown in Figure 7 for moderate stall case and in Figure 8 for deep stall case. It can be found that the stall flutter oscillations are not effectively suppressed via the adaptive pitch controller in 5 seconds even though there is tendency of decaying for both stall cases. At the same time, even though the classic flutter controller works for the pitch mode and performs better than the adaptive pitch controller on the plunge mode, the oscillations of the plunge displacement cannot be totally suppressed in 5 seconds as they do for classic flutter case. The better control performance of pitching than plunging is due to control design with system output of pitching signal, as indicated in controller one and controller two. Therefore, those former flutter controllers are not good enough to eliminate the stall flutter effectively in a short time. Stall flutter controller needs to be designed with the investigation of new sensor signal and new control algorithm.

4.2. The Design of Stall Flutter Controller. In order to develop the effective stall flutter controller for both stall cases, there are several aspects that need to be investigated: first, the effective sensor signals (or the control input signals for the controller) that can control the aeroelastic behavior of the blade section undergoing dynamic stall significantly, second, the controllability of the microtab (the control capability of the actuator), and third, the powerful control algorithm that can suppress the asymmetric LCOs of the stall flutter in a short time. 

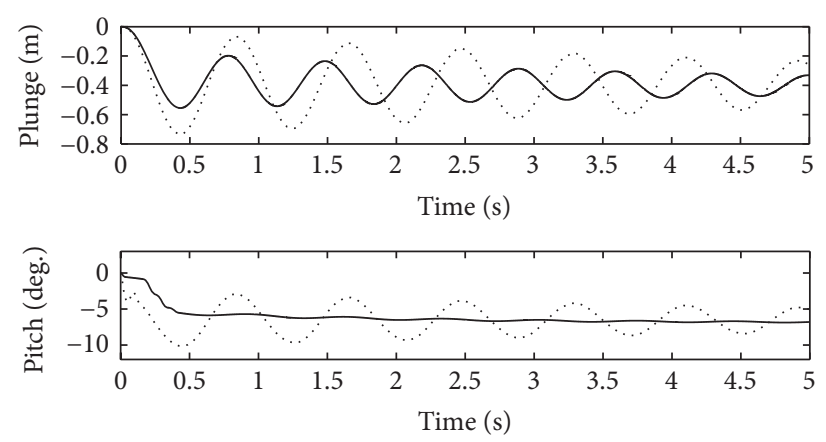

_ Classic flutter controller Adaptive pitch controller

Figure 7: System responses with classic flutter controller and adaptive pitch controller at moderate stall flutter case.
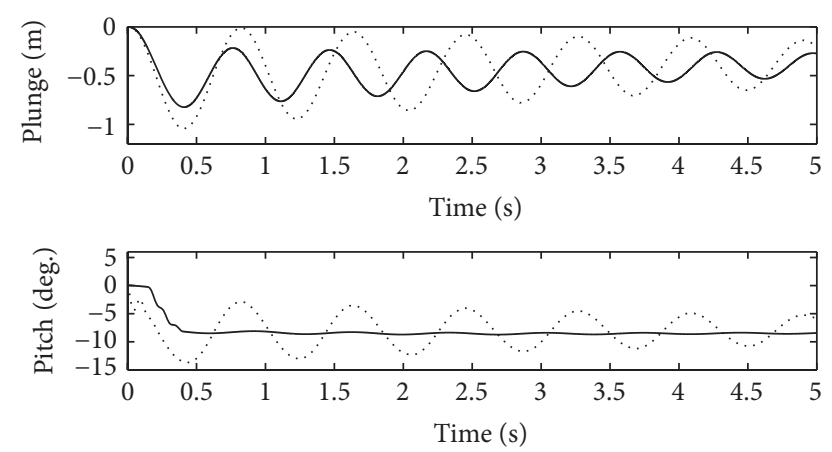

- Classic flutter controller Adaptive pitch controller

FIGURE 8: System responses with classic flutter controller and adaptive pitch controller at deep flutter case.

4.2.1. Sensor Signal Effect on Stall Flutter Control. To study the sensor signal effect on the control of stall flutter, the eigenvalues of the closed-loop system with a static output feedback of the sensor signal are analyzed. The state matrix of the closed-loop system is taken as $A_{c}=A+B G_{e} C, A=$ $\left.A(t)\right|_{\alpha^{0}(t)=11}$, for moderate stall case and $A=\left.A(t)\right|_{\alpha^{0}(t)=13.5}$ for deep stall case; $y=C q$ is the sensor signal. Note that the controllability matrix can also be computed to indicate the sensor signal effect, but here the eigenvalue analysis makes a more vivid explanation. The LCOs of the stall flutter indicate the imaginary stability of open-loop system.

For moderate stall flutter case, Figure 9 illustrates the eigenvalues of plunge and pitch modes in closed-loop systems with different sensor signals. It is revealed that the sensor of $h$, the sensor of $\theta$, and the sensor of $\dot{\theta}$ all lose the controllability of the plunge mode in stall flutter, even though they can have the full controllability of the pitch mode. Nevertheless, both the sensor of $\dot{h}$ and the sensor of $\dot{h}+\dot{\theta}$ can suppress the LCOs with no imaginary parts in plunge mode and all negative values in pitch mode. Among those two sensor signals, the sensor of $\dot{h}+\dot{\theta}$ is more influential in control of moderate stall flutter. Note that, for consideration of the sensor number limitation or sensor cost in practice, the single
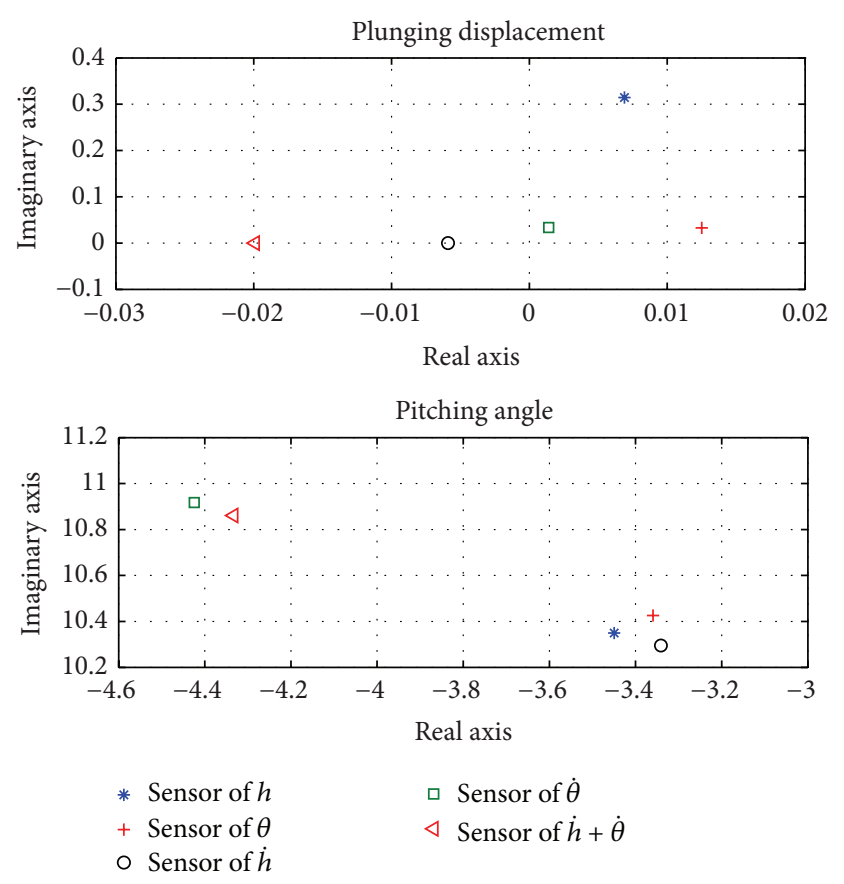

Figure 9: Closed-loop eigenvalues of the system with different sensor signals for moderate stall case.
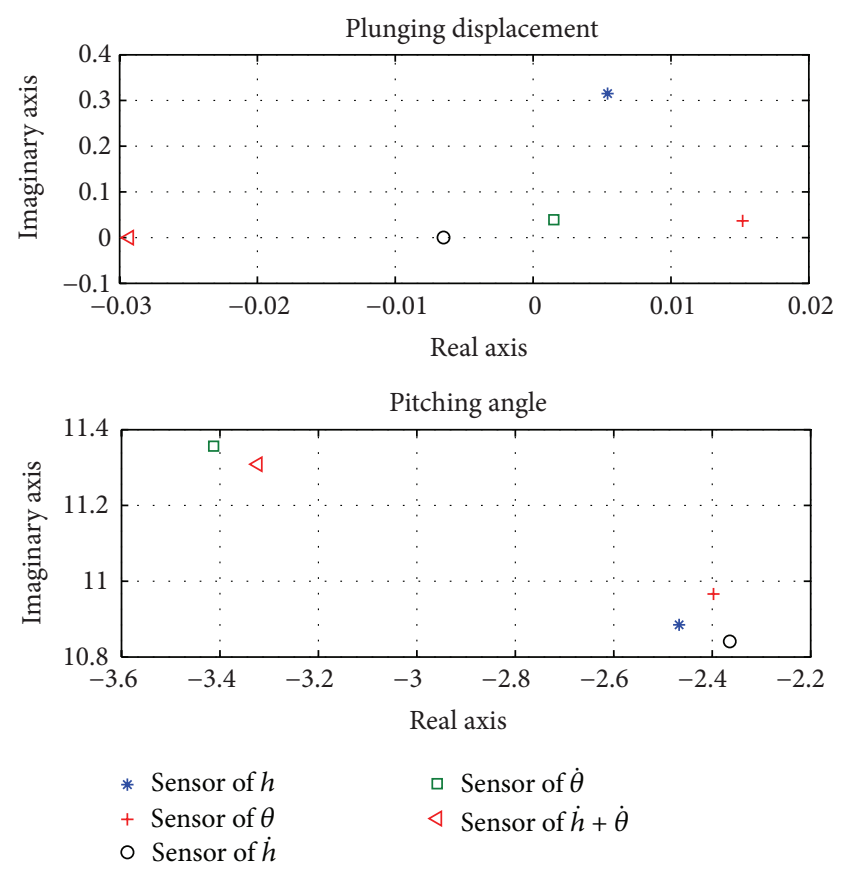

Figure 10: Closed-loop eigenvalues of the system with different sensor signals for deep stall case.

sensor signal of $\dot{h}$ can be chosen for implementation. For deep stall flutter case, the eigenvalues results shown in Figure 10 are similar with those for moderate stall flutter case with little less negative values in pitch mode. 

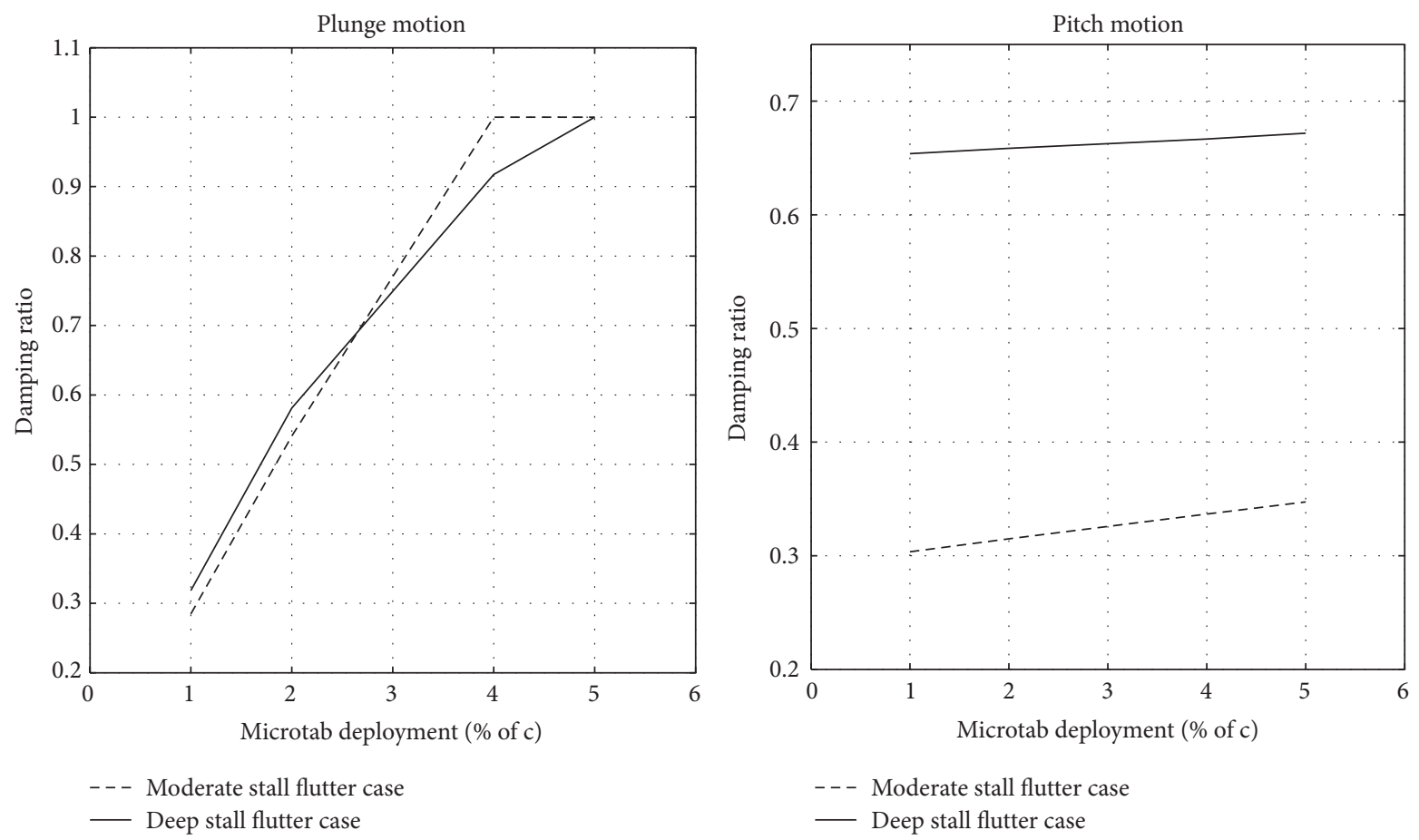

FIGURE 11: Damping ratios versus microtab limitation for moderate/deep stall flutter cases.

4.2.2. Microtab Control Analysis on Stall Flutter. Since the potential sensor signals are studied for both stall flutter cases, the limitation of the microtab deployment also needs to be considered for practice. The airfoil type is DU97W30010 , and the location of the microtab is at $100 \%$ chord. The deployment of the microtab is saturated to $1 \%-5 \%$ of chord. The aerodynamic coefficients are adopted with respect to the deployment of the microtab. The static test curves of aerodynamic coefficients without/with microtab and with different microtab deployments are detailed in [29]. In this section, four different limitations of the microtab deployment are tested to verify the control capability of the microtab on LCOs of moderate/deep stall flutter.

The damping ratios of plunge and pitch modes in the feedback system with microtab limitations (1\% of c, $2 \%$ of c, $4 \%$ of c, and $5 \%$ of c) are illustrated in Figure 11. It is clear that both modes have increasing damping ratios (a sharp increase in plunge damping ratio and a moderate increase in pitch damping ratio) with the growing microtab deployments, indicating that the LCOs in both stall flutter cases can be successfully suppressed within the limitations of the microtab. And the microtab has more control ability on plunge mode than pitch mode.

For the control of plunge motion, small microtab limitation (e.g., 1-2\% of c) leads to the decaying LCOs with small damping ratios less than one, and full microtab deployment (5\% of c) brings completely damped responses with damping ratio of 1 for both stall flutter cases. However, the microtab deployment of $4 \%$ of $\mathrm{c}$ has a weaker impact on deep stall flutter with less damping ratio than that of moderate stall flutter case, revealing that it is a little harder to suppress the deep stall flutter compared to moderate stall flutter.
For the control of pitch motion, although there is a small increase in damping ratio, the microtab seems to have similar effect on the increase of the damping ratio for both stall flutter cases. Thus, microtab is proved as the potential and effective actuator for the stall flutter control, with powerful deployment of $4 \%$ of $\mathrm{c}$ for moderate stall case and $5 \%$ of $\mathrm{c}$ deployment for deep stall case.

4.2.3. Stall Flutter Controller. The control objective is to minimize the asymmetric LCOs in the stall flutter. Since the former aeroelastic controllers do not have capability in stall flutter control, the controller needs to be improved with new control strategies or new effective sensor signal for the stall flutter application. In this section, two different stall flutter controllers are developed based on different control algorithms and the new potential sensor signal for stall flutter control.

Simple Stall Flutter Controller. First, the simple output feedback control strategy used for classic flutter control is adopted to design the stall flutter controller along with the new potential sensor signal in Section 4.2.1. Then, the simple stall flutter controller is given as

$$
\begin{aligned}
& u=G_{e} y, \\
& y=\dot{h}+\dot{\theta} .
\end{aligned}
$$

Note that, on this condition, the stall flutter control system is taken as a single input and single output system.

Adaptive Stall Flutter Controller. To improve the control capability of each vibration mode, the stall flutter control 


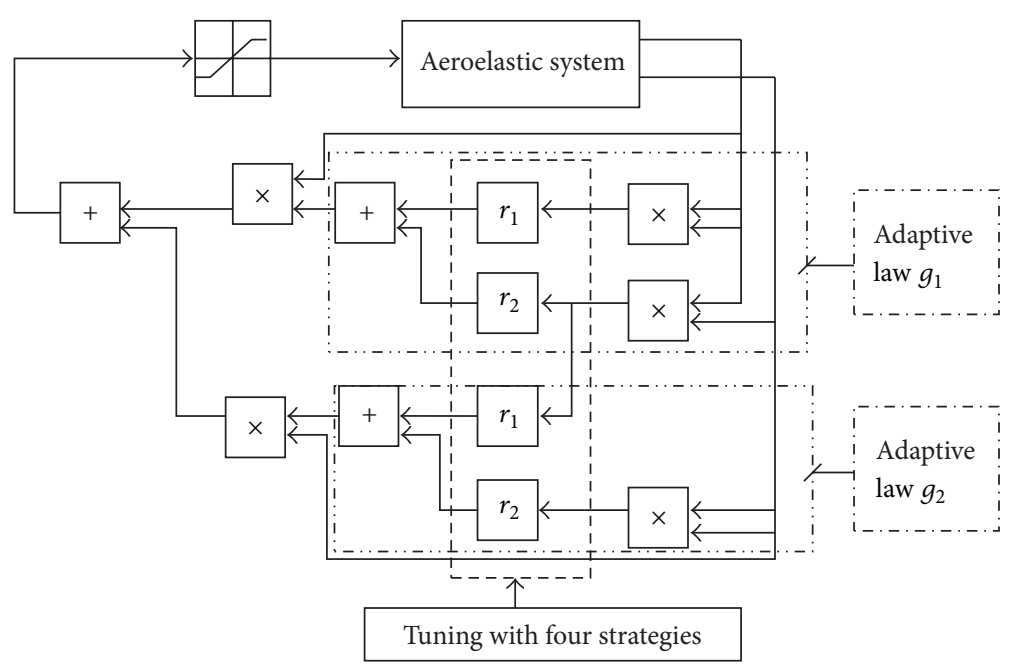

FIGURE 12: Block diagram of the adaptive stall flutter control strategy.

system is treated as a single-input two-output system, and the adaptive control is used as the control algorithm. The block diagram of the adaptive stall flutter control strategy is illustrated in Figure 12. Here, the output of the system is defined as the vector $y=\left[\begin{array}{ll}\dot{h} & \dot{\theta}\end{array}\right]^{T}$. Since the system is time-varying, the control gain should also be designed to accommodate with the time-varying change of system parameters.

The adaptive stall flutter controller is presented as

$$
\begin{aligned}
u & =G_{e}(t) y, \\
G_{e}(t) & =\left[\begin{array}{ll}
g_{1}(t) & g_{2}(t)
\end{array}\right],
\end{aligned}
$$

where $G_{e}(t)$ is the time-varying adaptive control gain, which can be updated by the adaptive law as

$$
\begin{aligned}
& g_{1}(t)=r_{1} \dot{h}^{2}+r_{2} \dot{h} \dot{\theta}, \\
& g_{2}(t)=r_{1} \dot{h} \dot{\theta}+r_{2} \dot{\theta}^{2},
\end{aligned}
$$

where $r_{1}$ and $r_{2}$ are scalar. The adaptive law can regulate the change of adaptive control gain to make plunge displacement $h$ and pitch angle $\theta$ asymptotically stable.

Since the value of $r_{1}$ and $r_{2}$ can impact the performance of the adaptive law, four strategies of $r_{1}$ and $r_{2}$ are studied for the stall flutter control: case $1, r_{1}=-1$ and $r_{2}=-1$, case 2, $r_{1}=-1$ and $r_{2}=-0.1$, case $3, r_{1}=-0.1$ and $r_{2}=-1$, and case $4, r_{1}=$ -0.5 and $r_{2}=-0.5$. First, the control responses of adaptive stall flutter controllers with case 1 , case 2, and case 3 are compared in Figure 13. It can be revealed that the controller with all control strategy cases can suppress the LCOs of plunge and pitch modes in 5 seconds as expected. However, the control strategy of case 2 leads to high-frequency pitch oscillations in first 2 seconds for moderate stall case and even as long as 4 seconds for deep stall case because case 2 lacks control power in pitch mode with $\left|r_{1}\right| \ll\left|r_{1}\right|$. At the same time, case 3 performs well in pitch oscillation suppression, while it performs worse in plunge mode among all three cases because of $\left|r_{1}\right| \ll\left|r_{1}\right|$. Only case 1 which has equivalent weigh on both modes $\left(\left|r_{1}\right|=\left|r_{2}\right|\right)$ can suppress all LCOs effectively. The unsatisfying control results of case 2 and case 3 are due to the fact that there is not very strong coupling between pitching and plunging under dynamic stall condition. Hence, the individual control of either plunging or pitching cannot suppress them all effectively at the same time. In order to further investigate the effect of $r_{1}$ and $r_{2}$, the controller with case 4 is compared with that with case 1 in Figure 14. It is shown that the decrease of value of $\left|r_{1}\right|,\left|r_{1}\right|$ brings the similar overshoot of the control response but with a longer settling time, especially for the plunge control. All in all, the adaptive stall flutter control with control strategy of case 1 is the most potential one for LCOs suppression for both stall flutter cases.

4.3. Control Results. To show the superiority of the proposed adaptive stall flutter controller, it is compared with the simple stall flutter controller in (20). The results of control performance with those controllers are shown in Figure 15. In addition, the effects of adaptive stall flutter control on moderate stall flutter and deep stall flutter are illustrated in Figure 16.

4.3.1. Simple Stall Flutter Controller versus Adaptive Stall Flutter Controller. Figure 15 shows the control results of the simple flutter controller and the adaptive stall flutter controller. With respect to the classic flutter controller in Section 4.1, the simple flutter controller has improved control performance on plunge mode with the new sensor signal. Specifically, the plunge displacement has a quick decay of the oscillations at the first several simulation intervals with a relatively short settling time and small magnitude of the oscillations, which confirms the effectiveness of the new sensor signal in the stall flutter control. In other words, the sensor signal has a significant impact on the improvement of the control effect on different flutter cases even with the same control algorithm. 

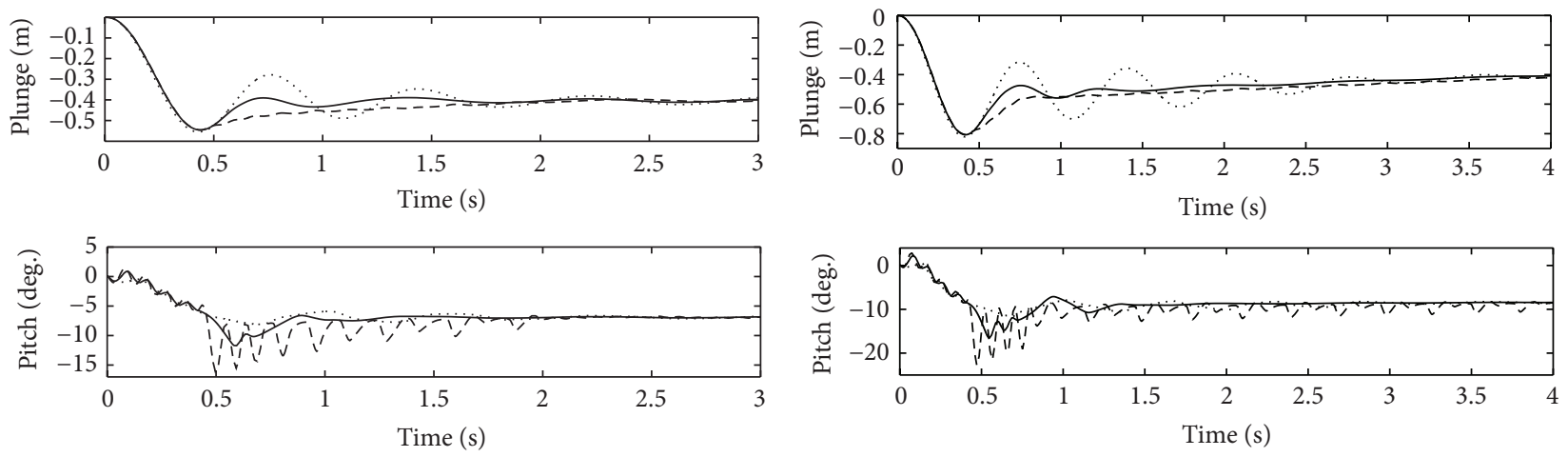

$$
\begin{array}{ll}
- & r_{1}=r_{2}=-1 \\
--- & r_{1}=-1, r_{2}=-0.1 \\
\ldots . . & r_{1}=-0.1, r_{2}=-1
\end{array}
$$$$
\text { - } r_{1}=r_{2}=-1
$$$$
-r_{1}=-1, r_{2}=-0.1
$$$$
\text { …. } r_{1}=-0.1, r_{2}=-1
$$

(a) Moderate stall flutter case

(b) Deep stall flutter case

FIGURE 13: Adaptive stall flutter control responses with different control strategies for (a) moderate stall flutter case and (b) deep stall flutter case.
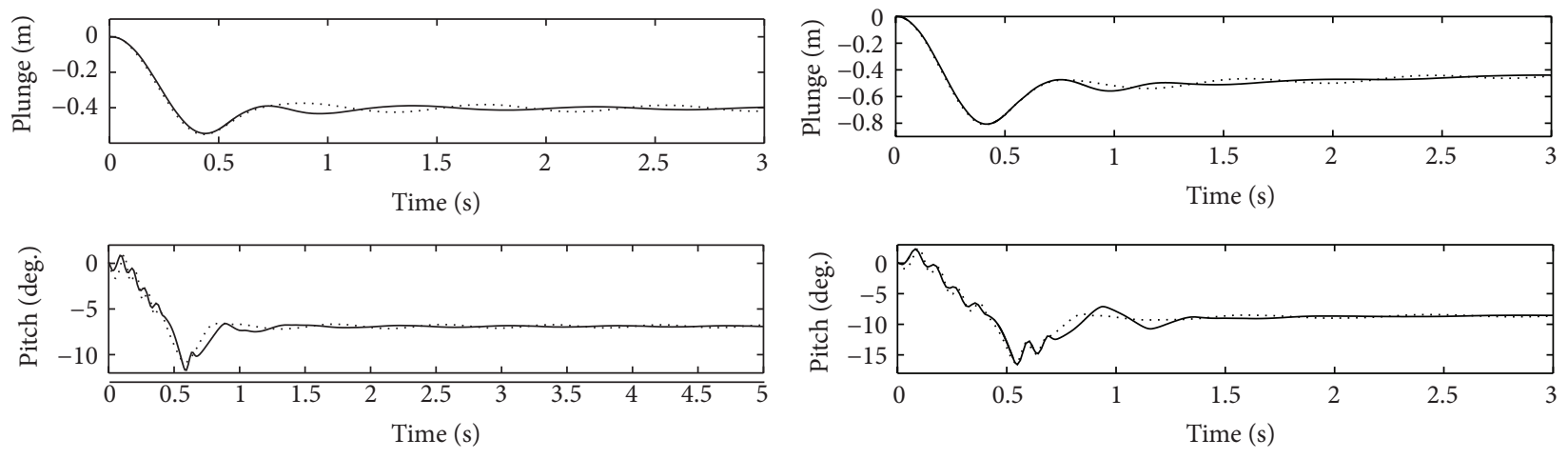

$$
\begin{aligned}
r_{1} & =r_{2}=-1 \\
\ldots \ldots & r_{1}=r_{2}=-0.1
\end{aligned}
$$

(a) Moderate stall flutter case

$$
\begin{aligned}
& r_{1}=r_{2}=-1 \\
& \cdots \quad r_{1}=r_{2}=-0.1
\end{aligned}
$$

(b) Deep stall flutter case

Figure 14: Adaptive stall flutter control responses with different equal-weigh control strategies for (a) moderate stall flutter case and (b) deep stall flutter case.
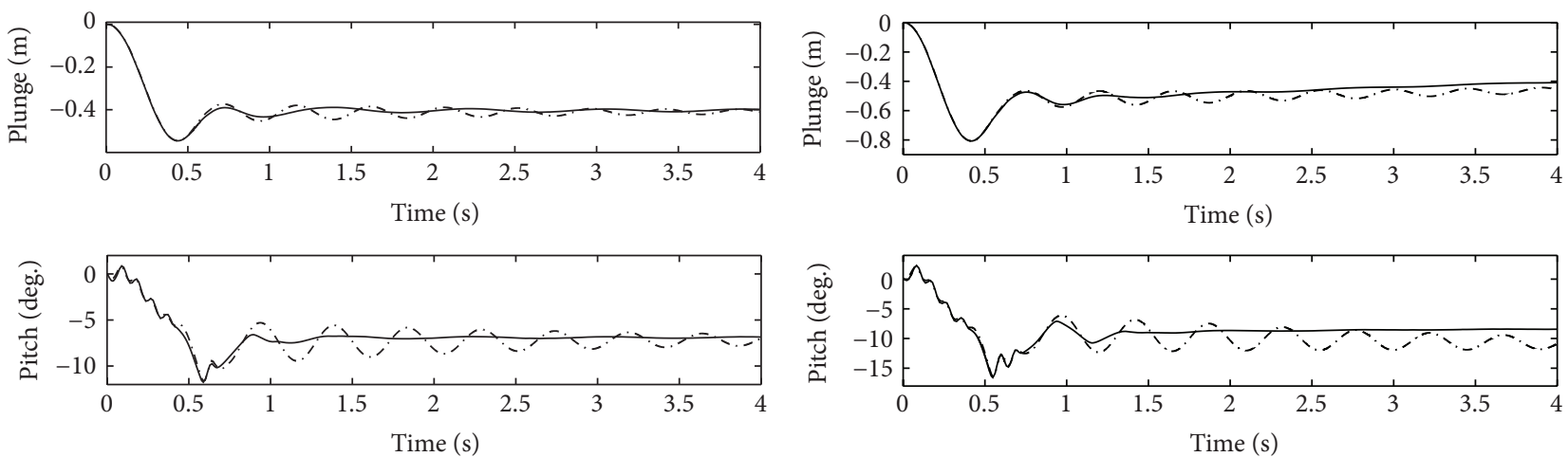

- - Simple stall flutter controller

- Adaptive stall flutter controller

-. - Simple stall flutter controller
_ Adaptive stall flutter controller

(a) Moderate stall flutter case

(b) Deep stall flutter case

FIGURE 15: Response of the closed-loop system with simple stall flutter controller and adaptive stall flutter controller for (a) moderate stall flutter case and (b) deep stall flutter case. 

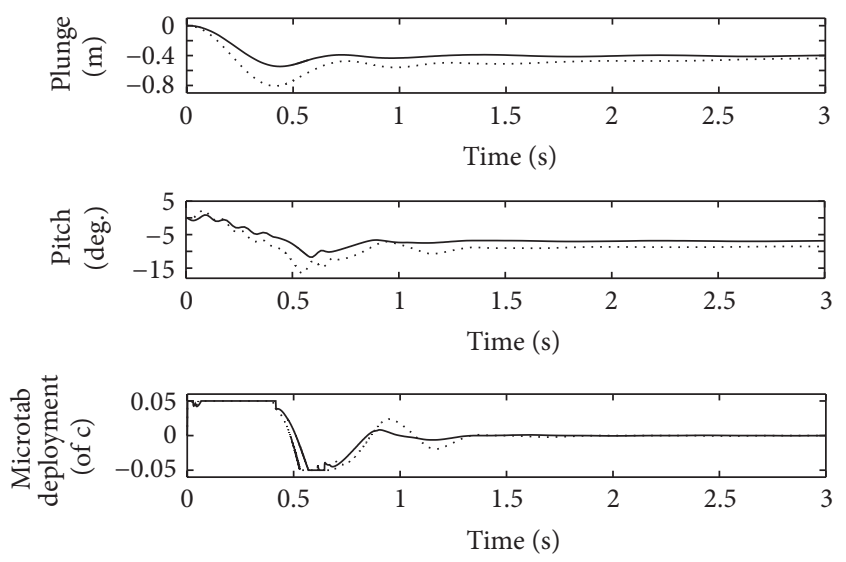

_ Moderate stall case

..... Deep stall case

Figure 16: Control results of the closed-loop system for moderate/deep stall flutter cases.

Although the simple flutter controller can effectively suppress the LCOs and stabilize the plunged mode in about 4 seconds and the pitch mode at the same time, the dynamic performance is not very satisfying with lots of small oscillations around the steady state after 1 second, which indicate that the utilization of only new sensor signal is not powerful enough to eliminate all vibrations in a short time for both modes. In contrast, the adaptive stall flutter controller shows the superiority with the new control algorithm and the new sensor signal. As indicated in Figure 15, for moderate stall case, the proposed adaptive stall flutter controller greatly improves the control performance of pitch and plunge modes. Both vibration responses can converge to the steady state in 2 seconds, and there are no significant oscillations after 1.5 seconds to show the great dynamic performance. However, the static stall flutter controller is not capable of suppressing all oscillations in a short time even though it can stabilize the system with the decaying responses for all stall cases. For deep stall flutter with stronger dynamic stall, simple stall flutter controller performs even worse with larger oscillations in vibration modes, while the adaptive stall flutter control can still suppress the stall flutter quickly with good dynamic performance. Thus, the adaptive stall flutter controller outperforms the static stall flutter controller.

For the physical meaning, first, the poor control performance of the classic flutter controller on pitching control is due to the weak coupling between pitching and plunging on stall flutter cases. Then, this weak coupling is strengthened at specific operation point by the simple stall flutter controller with new sensor signal, which is the most potential sensor signal in stall flutter control. However, as the parameters of the system are varying from one operation point to another, the coupling dynamic is also changing from time to time. On this condition, the simple stall flutter controller cannot adapt to the coupling variance with the constant control gain. Nevertheless, the proposed adaptive stall flutter controller can adapt to the varying coupling conditions at different operation points and adjust the control input by the adaptive law. Overall, there is improvement of the proposed adaptive stall flutter controller on the following aspects: (1) involving both of plunge acceleration and pitch rate in system output signal instead of only pitch rate for the output feedback control, (2) adding the cross term of $\dot{h} \dot{\theta}$ in the adaptive control law in (22), and (3) distributing the equal weigh on the control of plunged mode and pitch mode with $r_{1}=$ -1 and $r_{2}=-1$ in (22). All those new control strategies can strengthen the coupling between pitching and plunging along the whole system trajectory and further improve the overall control performance. Hence, the proposed adaptive stall flutter controller is the effective and robust controller for the stall flutter suppression.

4.3.2. Moderate Stall Flutter Control versus Deep Stall Flutter Control. Figure 16 illustrates the control responses of the adaptive stall flutter control of both moderate and deep stall flutter cases. For both stall flutter cases, the proposed adaptive stall flutter controller has the full controllability of both vibration modes, and it can suppress all LCOs with good dynamic performance in a short time within the saturation of the microtab.

However, the control effect in moderate stall flutter seems a little better than that of deep stall flutter. It can be found clearly that, compared with the moderate flutter case, the system responses of the deep stall flutter system tend to have a relatively larger overshoot, larger steady state error, and longer settling time, and the system needs more actuation of the microtab at around 1 second, when the system responses begin to converge. Therefore, it is more difficult to suppress the deep stall flutter than the moderate stall flutter. Note that the responses of the microtab deployment can quickly converge to zero after 1.5 seconds, which also confirms the fast actuation and the control capability of the microtab.

The control results can be verified by the results of microtab control analysis on stall flutter. As indicated in Figure 11, the damping ratio of both plunge and pitch modes in stall flutter can be increased by the actuator of microtab with more significant improvement of plunge damping ratio than pitch damping ratio, which confirms the better control performance of plunge displacement with more smooth response in Figure 16. At the same time, Figure 11 shows that damping ratios for moderate stall flutter can be improved in a better way than that for deep stall flutter, which verifies the conclusion of control results demonstrating that deep stall flutter control is tougher than the moderate stall flutter control.

The control results in Figure 16 are reasonable and can also be confirmed by physical explanation. Since the sharp change in aerodynamic loads for deep stall case leads to severe change of the coupling of vibration modes, the controller is more reluctant to the rapid change of the system dynamic and it will definitely need more power from the actuator to bond the strong coupling between vibration modes and gain the steady conditions.

\section{Conclusion}

In this study, the control of asymmetric LCOs of the moderate/deep stall flutter is investigated. The moderate/deep 
dynamic stall conditions of the blade section are first simulated based on experimental data, and the corresponding moderate/deep stall flutters are analyzed separately. The adaptive stall flutter controller is designed and studied for effective moderate/deep stall flutter control. The superiority of the proposed controller is proved by the comparison with other aeroelastic controllers. The conclusions can be made based on the results as follows.

(1) The proposed aeroelastic model is capable of predicting the different dynamic stall conditions of the section with the simulation results of dynamic lift owing to expected overshoot and dynamic moment revolving around the static curves. The stall flutter analysis shows that, compared with the moderate stall flutter, the deep stall flutter can further decrease the damping ratio of the pitch and plunge modes, leading to relatively large asymmetric LCOs in a shorter time.

(2) The passive microtab control is rarely studied in the field of moderate/deep stall flutter. For the design of effective stall flutter controller via microtab, several aspects are investigated. The sensor signal study shows that the sensor of $\dot{h}+\dot{\theta}$ is more influential in control of stall flutter, and the signal sensor of $\dot{h}$ also works for LCOs suppression for both plunge and pitch mode. Moreover, microtab is proved as the potential and effective actuator for the stall flutter control, with a sharp increase of damping ratio in plunge mode and a moderate increase of damping ratio in pitch mode. Furthermore, the control strategy study reveals that the equivalent weigh on the gains in adaptive law of the adaptive stall flutter controller leads to more satisfactory control performances at both stall flutter cases.

(3) The superiority of the proposed adaptive stall flutter controller is proved by the comparison with the simple stall flutter controller. The simulation results illustrate that the proposed stall flutter controller performs better in LCOs suppression with great dynamic performance. In addition, the deep stall flutter is more difficult to control than the moderate stall flutter.

The future work includes the implementation of the proposed control method on the $3 \mathrm{D}$ wind turbine blade. For $3 \mathrm{D}$ geometries, the vibration control is more difficult and complicated since the vibration modes increase to three degrees of freedom motions. The aeroservoelastic model for the $3 \mathrm{D}$ wind turbine blade should be established for the control design. In order to solve the control problem for $3 \mathrm{D}$ blade, the adaptive controller should be redesigned for all three vibration modes, and new control strategies in the control law should be adopted to achieve the best control performance.

\section{Competing Interests}

The authors declare that there are no competing interests regarding the publication of this paper.

\section{Acknowledgments}

The authors acknowledge support of this work through Grant no. 14KJB480006 from the Natural Science Foundation of the Colleges and Universities in Jiangsu Province, Grant no. 2015CXJ024 from School Innovation Fund of Yangzhou University, and Grant no. DESC0001261 from Department of Energy, USA. The project is also sponsored by the Scientific Research Foundation for the Returned Overseas Chinese Scholars, State Education Ministry.

\section{References}

[1] G. Dimitriadis and J. Li, "Bifurcation behavior of airfoil undergoing stall flutter oscillations in low-speed wind tunnel," AIAA Journal, vol. 47, no. 11, pp. 2577-2595, 2009.

[2] W. J. McCroskey, "The phenomenon of dynamic stall," NASA TM81264, 1981.

[3] J. Yan and Y. Xin, "Oscillatory blowing control numerical simulation of airfoil flutter by high-accuracy method," Journal of Aircraft, vol. 41, no. 3, pp. 610-615, 2004.

[4] A. J. Kurdila and M. R. Akella, "Nonlinear control methods for high-energy limit cycle oscillations," Journal of Guidance, Control, and Dynamics, vol. 24, no. 1, pp. 185-192, 2001.

[5] T. W. Strganac, J. Ko, and D. E. Thompson, "Identification and control of limit cycle oscillations in aeroelastic systems," Journal of Guidance, Control, and Dynamics, vol. 23, no. 6, pp. 1127-1133, 2000.

[6] L. Librescu and P. Marzocca, "Advances in the linear/nonlinear control of aeroelastic structural systems," Acta Mechanica, vol. 178, no. 3-4, pp. 147-186, 2005.

[7] D. Tang and E. H. Dowell, "Flutter/LCO suppression for highaspect ratio wings," Aeronautical Journal, vol. 113, no. 1144, pp. 409-416, 2009.

[8] X. G. Li and S. Fleeter, "Active suppression if nonlinear stall flutter using piezoelectric actuators," International Journal of Turbo and Jet-Engines, vol. 21, no. 2, pp. 69-85, 2004.

[9] Z. Sun, S. Haghighat, H. H. T. Liu, and J. Bai, “Time-domain modeling and control of a wing-section stall flutter," Journal of Sound and Vibration, vol. 340, pp. 221-238, 2015.

[10] T. Liu, "Aeroservoelastic pitch control of stall-induced flap/lag flutter of wind turbine blade section," Shock and Vibration, vol. 2015, Article ID 692567, 20 pages, 2015.

[11] D. W. Lobitz, "Flutter speed predictions for MW-sized wind turbine blades," Wind Energy, vol. 7, no. 3, pp. 211-224, 2004.

[12] D. G. Wilson, D. E. Berg, M. F. Barone, J. C. Berg, B. R. Resor, and D. W. Lobitz, "Active aerodynamic blade control design for load reduction on large wind turbines," in Proceedings of the European Wind Energy Conference and Exhibition (EWEC '09), pp. 643-678, Marseille, France, March 2009.

[13] M. D. Conner, D. M. Tang, E. H. Dowell, and L. N. Virgin, "Nonlinear behavior of a typical airfoil section with control surface freeplay: a numerical and experimental study," Journal of Fluids and Structures, vol. 11, no. 1, pp. 89-109, 1997.

[14] D. T. Yen, C. P. Van Dam, F. Bräeuchle, R. L. Smith, and S. D. Collins, "Active load control and lift enhancement using MEM translational tabs," in Proceedings of the AIAA Fluids Conference and Exhibit, AIAA Paper 2000-2422, Denver, Colo, USA, June 2000.

[15] C. P. Van Dam, D. Y. Nakafuji, C. Bauer, K. Standish, and D. Chao, "Computational design and analysis of a microtab based aerodynamic loads control system for lifting surfaces," in MEMS Components and Applications for Industry, Automobiles, 
Aerospace, and Communication II, Proceedings of SPIE, pp. 2531, SPIE International Society for Optical Engineers, San Jose, Calif, USA, January 2003.

[16] M. D. Maughmer and G. Bramesfeld, "Experimental investigation of Gurney flaps," Journal of Aircraft, vol. 45, no. 6, pp. 20622067, 2008.

[17] P. Baek, M. Gaunaa, N. N. Sørensen, and P. Fuglsang, "Comparative study of distributed active load control concepts for wind turbine blades," in Proceedings of the Science of Making Torque from Wind Conference (Torque '10), pp. 611-617, Heraklion, Greece, June 2010.

[18] D. G. Wilson, D. E. Berg, D. W. Lobitz, and J. R. Zayas, “Optimized active aerodynamic blade control for load alleviation on large wind turbines," in Proceedings of the AWEA Wind Power Conference \& Exhibition, pp. 1-4, Houston, Tex, USA, June 2008.

[19] J. P. Baker, K. J. Standish, and C. P. van Dam, "Two-dimensional wind tunnel and computational investigation of a microtab modified airfoil," Journal of Aircraft, vol. 44, no. 2, pp. 563-572, 2007.

[20] D. T. Yen Nakafuji, C. P. Van Dam, R. L. Smith, and S. D. Collins, "Active load control for airfoils using microtabs," Journal of Solar Energy Engineering, vol. 123, no. 4, pp. 282-289, 2001.

[21] N. Li and M. J. Balas, "Adaptive flow control of wind turbine blade using microtabs with unsteady aerodynamic loads," in Proceedings of the IEEE Green Technologies Conference, pp. 134139, IEEE, Denver, Colo, USA, April 2013.

[22] N. Li and M. J. Balas, "Aeroelastic control of a wind turbine blade using microtabs based on UA97W300-10 airfoil," Wind Engineering, vol. 37, no. 5, pp. 501-516, 2013.

[23] N. Li and M. J. Balas, "Flutter suppression of rotating wind turbine blade based on Beddoes-Leishman model using microtabs," in Proceedings of the AIAA Modeling and Simulation Technologies Conference (MST '13), AIAA 2013-5078, American Institute of Aeronautics and Astronautics, Boston, Mass, USA, 2013.

[24] N. Li and M. J. Balas, "Direct Periodic Adaptive Control of the aerodynamic loads of a rotating wind turbine blade using microtabs," in Proceedings of the American Control Conference (ACC '14), pp. 4428-4433, Portland, Ore, USA, June 2014.

[25] N. Li, M. J. Balas, H. Yang, W. Jiang, and K. T. Magar, "Numerical investigation of flapwise-torsional vibration model of a smart section blade with microtab," Shock and Vibration, vol. 2015, Article ID 136026, 11 pages, 2015.

[26] M. H. Hansen, M. Gaunaa, and H. A. Hadsen, "A beddoesleishman type dynamic stall model in state-space and indicial formulations," Tech. Rep. Risø-R-1354, Risø National Laboratory, Roskilde, Denmark, 2004.

[27] J. W. Naughton, J. Strike, M. D. Hind, A. S. Magstadt, and A. L. Babbitt, "Measurements of dynamic stall on the DU wind turbine airfoil series," in Proceedings of the 69th American Helicopter Society International Annual Forum 2013, pp. 26632676, Phoenix, Ari, USA, May 2013.

[28] B. S. Kallesøe, "A low-order model for analysing effects of blade fatigue load control," Wind Energy, vol. 9, no. 5, pp. 421-436, 2006.

[29] P. Nikoueeyan, J. A. Strike, A. S. Magstadt, M. D. Hind, and J. W. Naughton, "Characterization of the static aerodynamic coefficients of a wind turbine airfoil with gurney flap deployment for flow control applications," in Proceedings of the 32nd AIAA Applied Aerodynamics Conference (AIAA '14), AIAA Paper 20142146, Atlanta, Ga, USA, June 2014. 


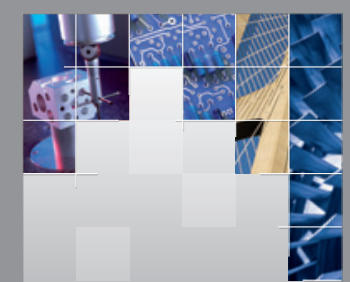

\section{Enfincering}
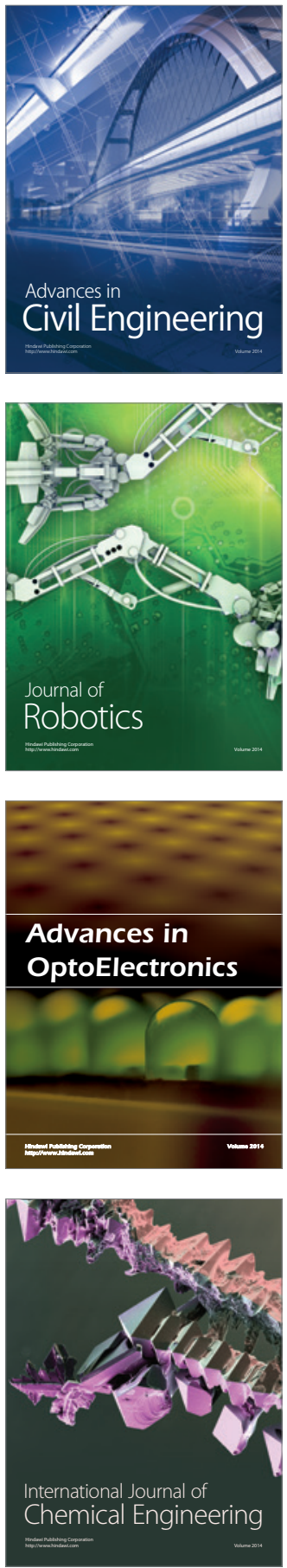

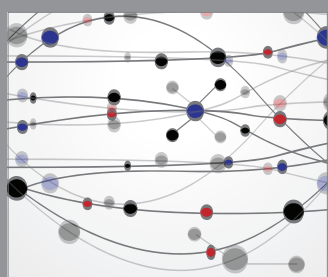

The Scientific World Journal

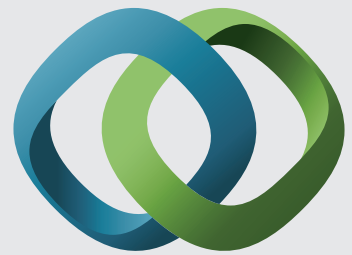

\section{Hindawi}

Submit your manuscripts at

http://www.hindawi.com
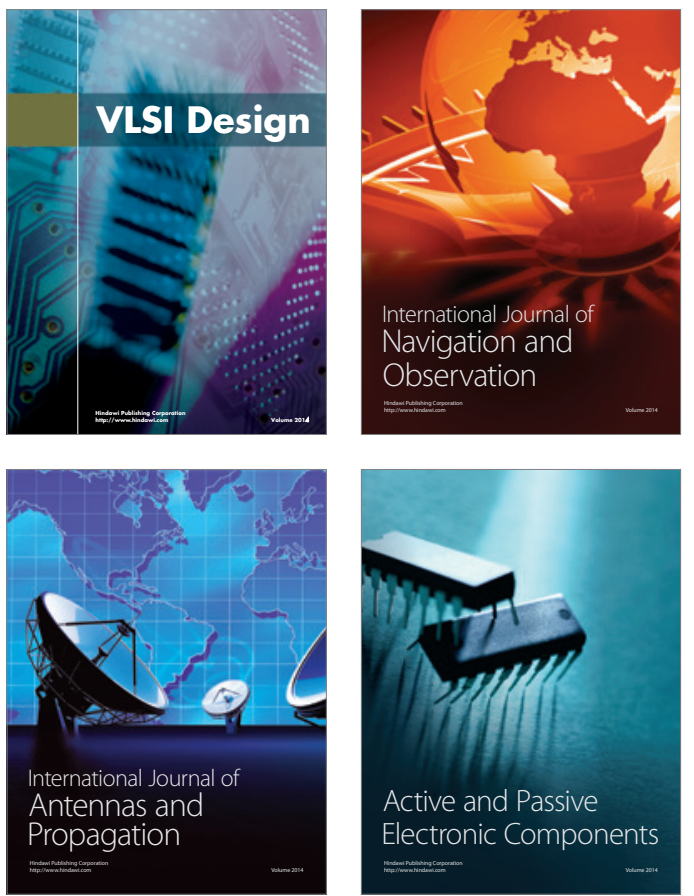
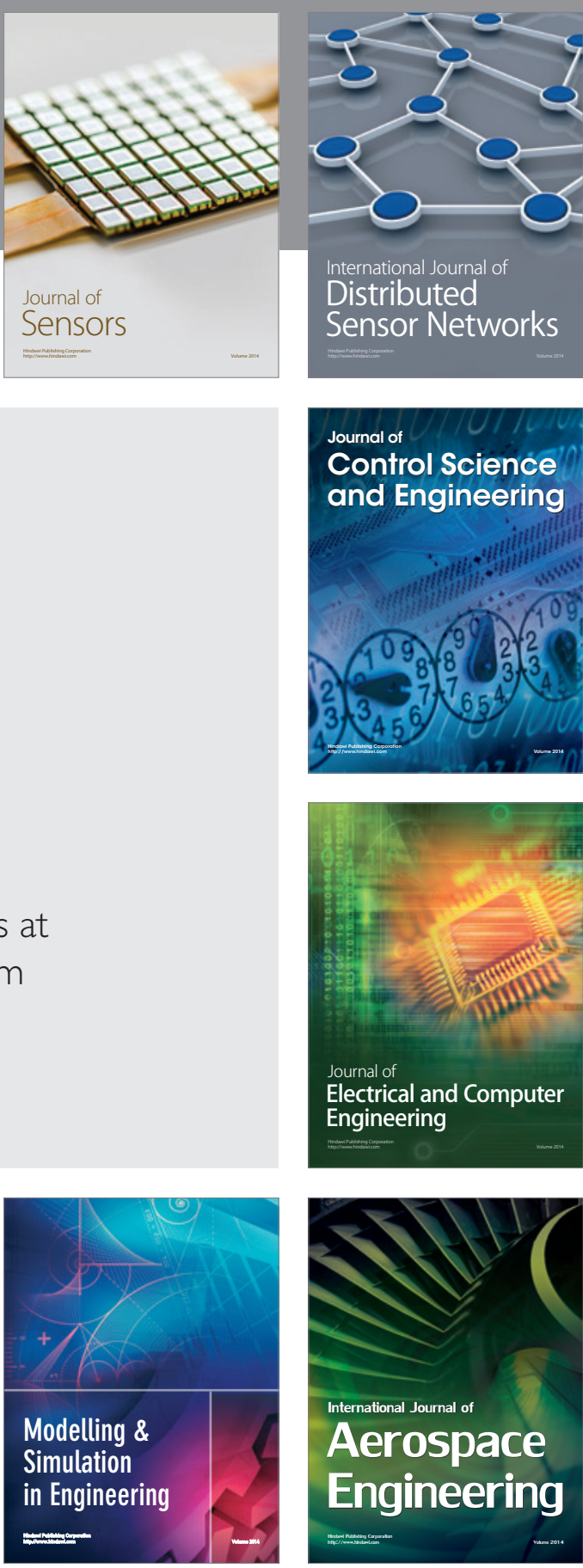

International Journal of

Distributed

Sensor Networks

Journal of

Control Science

and Engineering
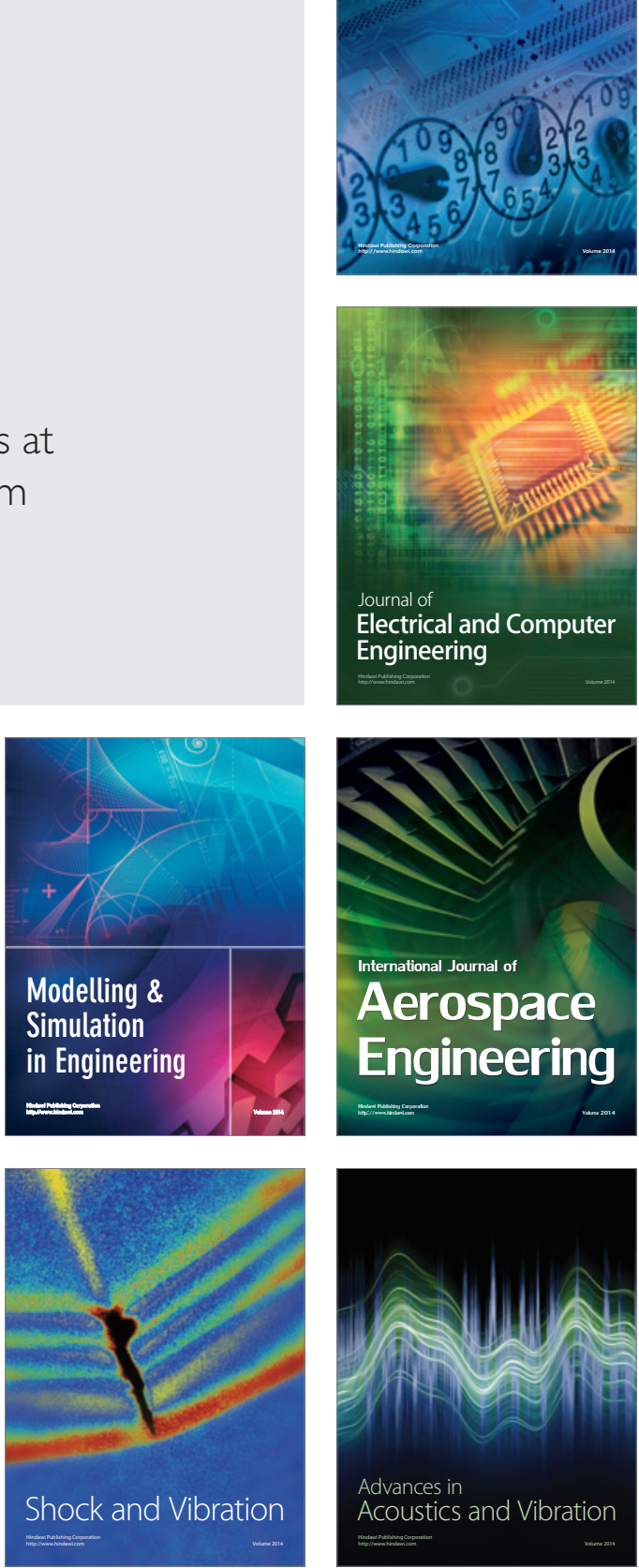